\title{
DEPOPULATION MECHANISM FOR INCOHERENT TERAHERTZ SOURCE - THz TORCH - BASED ON GaAsBi/GaAs QUANTUM WELL IN GaAs/AlGaAs PARABOLIC QUANTUM WELL
}

\author{
M. Karaliūnas ${ }^{a}$, A. Udal ${ }^{b}$, and G. Valušis ${ }^{a}$ \\ ${ }^{a}$ Department of Optoelectronics, Center for Physical Sciences and Technology, Sauletekio 3, 10257 Vilnius, Lithuania \\ ${ }^{\mathrm{b}}$ Department of Software Science, Tallinn University of Technology, Ehitajate tee 5, 19086 Tallinn, Estonia \\ Email: mindaugas.karaliunas@ftmc.lt
}

Received 29 November 2019; revised 7 February 2020; accepted 10 February 2020

\begin{abstract}
Parabolic quantum wells (PQWs) are known as a promising candidate for a compact terahertz (THz) source. $\mathrm{PQW}$ have equidistant subbands that can be designed to be separated by few $\mathrm{meV}$ to meet the $\mathrm{THz}$ frequency range. To enhance the efficiency and power of THz emission from PQWs, a new approach is proposed by employing depopulation of the lowest subbands of PQW. In this work, the theoretical analysis of an incoherent THz torch device is presented. The findings suggest that the introduction of narrower band-gap GaAsBi/GaAs rectangular quantum well within the GaAs/AlGaAs PQW can alter subbands arrangement to enable a faster depopulation mechanism exploiting LO phonon scattering. The calculated radiative power spectra show the increase of oscillator strength between the rearranged subbands of $\mathrm{PQW}$ due to the added GaAsBi rectangular potential. The increased intersubband radiative transition probability can lead to an efficient compact incoherent $\mathrm{THz}$ source - $\mathrm{THz}$ torch.
\end{abstract}

Keywords: terahertz emission, parabolic quantum well, GaAsBi/GaAs/AlGaAs nanostructures, incoherent THz source

PACS: 03.65.Ge, 73.21.Fg, 78.67.De, 33.20.Ea

\section{Introduction}

Terahertz $(\mathrm{THz})$ frequency waves are situated in the electromagnetic spectral range between microwave and far-infrared radiation from 0.1 to $10 \mathrm{THz}$. $\mathrm{THz}$ waves exhibit unique physical properties that can be used for many applications in spectroscopy, for instance, food inspection [1, 2], materials characterization [3] or medical diagnosis [4, 5]. $\mathrm{THz}$ imaging has opened new routes for application in discrimination of hidden or packaged objects [6, 月], medical characterization [8, 9] or nearfield sub-wavelength microscopy [10, 11]]. It can be possible because of the fact that many opaque to visible light materials, such as paper, plastic and cloth, are transparent to $\mathrm{THz}$ frequency waves, albeit many chemical compounds have unique signature $\mathrm{THz}$ spectrum absorption lines that identify the composition of the sealed content. The advan- tage is the non-ionizing and non-destructive nature of $\mathrm{THz}$ spectroscopy and imaging techniques that do not affect the samples under the test due to the small energy of $\mathrm{THz}$ radiation ranging from 0.4 to $41 \mathrm{meV}$ in terms of photon energy. Yet another emerging application field is sub- $\mathrm{THz}$ and $\mathrm{THz}$ range communication for high-speed, -volume data transmission due to the wide spectral band of radiation [12.

To fully enable advantages of $\mathrm{THz}$ spectroscopy and imaging as compared to other competing techniques, such as infrared spectroscopy and Xray imaging, and to expand the application field, compact and low-cost systems are required. For this purpose, a lot of efforts are dedicated to develop a new type of detectors [13, 14] and passive radiation beam manipulation elements, such as lenses, mirrors and beam-splitters [15-17]. In fact, the recent development of micro-detectors allowed 
one to achieve record values of sensitivity and noise equivalent power, in particular, employing heterodyning [18, 19] or homodyning [20] detection schemes. While the progress in the field of $\mathrm{THz}$ sensors has been impressive, the progress in the field of compact sources has been rather modest [21, 22].

Parabolic quantum wells (PQWs) are known as a promising candidate for a compact $\mathrm{THz}$ source. PQW has equidistant quantum energy subbands that can be designed to be separated by few $\mathrm{meV}$ to meet the $\mathrm{THz}$ frequency range [23]. Moreover, PQWs are little sensitive to thermal influence [24, 25] and applied electric fields [25, 26]. Therefore, the $\mathrm{THz}$ emission from PQWs was observed even at temperatures $T k_{\mathrm{B}}>\Delta E$, where $k_{\mathrm{B}}$ is the Boltzmann constant and $\Delta E$ is the energy difference between two adjacent subbands in the PQW [24].

Ulrich et al. reported the experimental value of electrically driven $\mathrm{THz}$ range $\mathrm{PQW}$ emitter efficiency to be $4.4 \times 10^{-8}$ [24]. In that work, the metal grading was used to extract the intersubband radiation from the PQW. In fact, better performance in the sense of efficiency was measured for the $140 \mathrm{~nm}$ width over the $200 \mathrm{~nm}$ PQW design that corresponds to the measured intersubband radiation emission at 2.2 over $1.6 \mathrm{THz}$, respectively. The emission was observed up to $240 \mathrm{~K}$ temperature and the increase of non-radiative lifetime was responsible for thermal quenching. In another work by Bratschitsch et al., coherent $\mathrm{THz}$ emission was measured from optically pumped intersubband plasmons in doped PQW, and apparently the field screening was responsible for the $\mathrm{THz}$ emission from the PQWs and not the quantum beats [25]. In that work, the 140-nm-wide PQW yielded the intersubband emission at $2.55 \mathrm{THz}$. The spectral emission line was observed up to $150 \mathrm{~K}$. The measured broadening of the line with increasing temperature suggested that increasing optical phonon scattering diminishes the $\mathrm{THz}$ intersubband radiation. Several other experimental works implement PQWs for advanced polaritonic $\mathrm{THz}$ emitters employing the strong light-matter coupling regime [27-30]. It is worth noting that all aforementioned studies employed the digital alloying technique for the growth of GaAs/AlGaAs PQWs.

Recently we have demonstrated the technological viability to grow the PQW GaAs/AlGaAs nanostructures using the analog alloying technique with molecular beam epitaxy and insertion of the GaAsBi rectangular quantum well (QW) at the centre of PQW with a high amount of Bi up to $6 \%$ [31]. Parabolically graded nanostructures showed superior interband radiative properties over the step-like and conventional rectangular QWs containing Bi. The enhancement in photoluminescence was attributed to the increased carrier trapping efficiency and pronounced localization effect on the GaAsBi QW created by PQW. In another recent work, we have reported the investigation results of undoped GaAs/AlGaAs PQW with a central GaAsBi QW optical response in the $\mathrm{THz}$ spectral range [32]. The study revealed the spectral features at 4.69 and $7.1 \mathrm{THz}$ that were tentatively attributed to the intersubband transitions of light holes in the valance band and electrons in the conduction band in GaAs/AlGaAs PQW grown using the analog alloying technique.

In this work, a new approach for an incoherent $\mathrm{THz}$ emitter based on GaAs/AlGaAs PQWs with carrier depopulation of the lowest subbands is proposed and theoretically analysed. Two designs for 2.5 and $7 \mathrm{THz}$ frequency emitters are modelled using the one-dimensional stationary Schrödinger equation solver for semiconductor heterostructures. The electron intersubband radiative lifetime is calculated for PQWs and quantum efficiency is estimated in respect to other electron scattering processes. The rectangular $\mathrm{GaAsBi} / \mathrm{GaAs} \mathrm{QW}$ is added to the centre of PQW to enable the carrier depopulation mechanism with a faster electron scattering with LO phonons. The quantum structures are modelled with the best arrangement of subbands and quantum efficiency is compared for electron intersubband radiative lifetime between the two lowest subbands with and without LO phonon scattering. Radiative power spectra of the 2.5 and $7 \mathrm{THz}$ frequency emitter designs are calculated to evaluate the impact of additional GaAsBi/GaAs QW potential at the bottom of GaAs/AlGaAs PQW on radiative properties. Finally, the $\mathrm{THz}$ torch device based on GaAs/ AlGaAs PQWs with a faster depopulation of the lowest PQW subbands is proposed.

\section{Modelling of PQWs for THz torch}

$\mathrm{GaAs} / \mathrm{Al}_{x} \mathrm{Ga}_{1-x}$ As PQWs with equidistant energy levels separated by 10.34 and $28.95 \mathrm{meV}$ to meet 
the frequency of 2.5 and $7 \mathrm{THz}$, respectively, are designed. The $\mathrm{Al}$ content $x$ in the outer barriers is set to $30 \%$ in the AlGaAs alloy. The room temperature band gap energy $1.426 \mathrm{eV}$ was taken for GaAs [33, 34] and, for AlGaAs barriers, the band gap was estimated using the linear dependence $E_{g}(x)=(1.426+1.247 x) \mathrm{eV}$ [35]. Then the room temperature $\mathrm{Al}_{0.3} \mathrm{Ga}_{0.7}$ As band gap energy is equal to $1.8 \mathrm{eV}$. The barrier potential height $V_{\mathrm{b}}$ for electrons is calculated accounting for $67 \%$ of total discontinuity in the conduction band and the rest in the valence band [36]. Then the barrier height for the conduction band $V_{\mathrm{b}}$ is $250.6 \mathrm{meV}$. The parabolic potential energy $V$ as a function on the distance in $z$ axis can be written as

$$
V(z)=V_{\mathrm{b}}\left[\left(\frac{2\left(z-z_{0}\right)}{l_{\mathrm{w}}}\right)^{2}+c_{\mathrm{q}}\left(\frac{2\left(z-z_{0}\right)}{l_{\mathrm{w}}}\right)^{4}\right],
$$

where $z_{0}$ is the coordinate of the PQW centre, $l_{\mathrm{w}}$ is the well width, and $c_{\mathrm{q}}$ is the empirical parameter to the weight quartic term set to 0.13 . The addition of quartic to square term compensates the effect of electron effective mass increase and improves the equidistant arrangement of subbands [37] as it is going to be elucidated later. For the electron effective mass $m^{*}$, the $\mathrm{Al}$ content dependent linear growth relation $m^{*}=(0.067+0.083 x) m_{0}$ was adopted [34, 38]. In terms of potential energy $V(z)$, this linear effective mass growth was redefined as $m^{*}=\left(0.067+c_{m} V(z)\right) m_{0}$ with the coefficient $c_{m}$ equal to $0.09936 \mathrm{eV}^{-1}$.

In addition to the PQW modelled using Eq. (1), a rectangular GaAsBi/GaAs QW formed by introducing bismuth to GaAs was created in the centre of PQW. In the case of bismuth, a strong band gap shrinking effect was taken into account by the coefficient $65 \mathrm{meV}$ per $1 \%$ of the Bi content $y$ and assuming $45 \%$ of narrowing to be associated with the conduction band [39]. In the $\mathrm{GaAs}_{1-y} \mathrm{Bi}_{y}$ region, the effective mass value $0.0592 m$ was set considering the experimental data $[31,40]$. Thus, Eq. (1) for the PQW potential energy for the $\mathrm{Al}_{x} \mathrm{Ga}_{1-x}$ As region is supplemented with $V(z)=0.45 y V_{\mathrm{bb}}$ for $|z| \leq l_{\mathrm{c}} / 2$ only and with limitation $V \leq V_{0}$, where $z$ is the coordinate accounted from the $\mathrm{GaAs}_{1-y} \mathrm{Bi}_{y} \mathrm{QW}$ centre, $l_{c}$ is the width of central rectangular $\mathrm{GaAs}_{1-y} \mathrm{Bi}_{y}$ potential, and $V_{\mathrm{bb}}=6.5 \mathrm{eV}$ is the potential height value for $\mathrm{GaBi}$.
With the above defined band parameters the one-dimensional stationary Schrödinger equation for semiconductor heterostructures with variable effective mass is solved,

$$
-\frac{\hbar^{2}}{2} \frac{\partial}{\partial} \frac{1}{m^{*}(z)} \frac{\partial \psi(z)}{\partial z}+V(z) \psi(z)=E \psi(z)
$$

using a numerical solver based on preliminary estimations of the shooting method combined with the accurate and fast-converging energy $E$ and the wavefunction $\psi(z)$ coupled solution method which in turn relays on the Newton convergence scheme and internal bordered tridiagonal matrix solver [41]. The transitions between initial $\psi_{\mathrm{i}}$ and final states $\psi_{\mathrm{f}}$ were characterized with the dipole matrix element [37]

$$
d_{\mathrm{if}}=\left\langle\psi_{\mathrm{i}}|z| \psi_{\mathrm{f}}\right\rangle .
$$

The oscillator strength $S_{\text {if }}$ is proportional to the square of $d_{\text {if }}$

$$
S_{\mathrm{if}}=\frac{2 m^{*}}{\hbar^{2}} h v_{\mathrm{if}} d_{\mathrm{if}}^{2},
$$

where $h v_{\text {if }} \equiv \Delta E$ is the energy difference between two subbands. Knowing the oscillator strength for transitions among every subband in the system, one can calculate the electron spontaneous emission radiative lifetime of intersubband transitions between any two initial and final states:

$$
\tau_{\mathrm{if}}^{\mathrm{rad}}=\frac{6 \pi \epsilon_{0} \mathrm{c}^{3} \hbar^{2}}{e^{2} n} \frac{m^{*}}{\left(h v_{\mathrm{if}}\right)^{2} S_{\mathrm{if}}}
$$

Here $n$ is the refractive index set to $3.3, \epsilon_{0}$ is the vacuum permittivity, $c$ is the speed of light, and $e$ is the elementary charge [37]. Then the radiative power spectrum can be calculated summing over all subbands in the PQW:

$$
P(\hbar \omega)=\sum_{\mathrm{i}>\mathrm{f}}^{N} \frac{\rho_{\mathrm{i}} h v_{\mathrm{if}} \Gamma}{\pi \tau_{\mathrm{if}}^{\mathrm{rad}}\left(\hbar \omega-h v_{\mathrm{if}}\right)^{2}+\Gamma^{2}} .
$$

Here $\rho_{\mathrm{i}}$ is the carrier density in each subband, $\Gamma$ is the spectral broadening set to $0.5 \mathrm{meV}$ for a better line resolution instead of typical $5 \mathrm{meV}$ [37]. The spectra are calculated with the constant carrier density in the subbands. 


\section{Results and discussion}

\subsection{PQW design for $\mathrm{THz}$ emission}

With only variable parameter being $l_{w}$, the best solutions for 2.5 and $7 \mathrm{THz}$ PQWs are shown in Fig. $1(a, b)$, respectively. The first design contains 24 equidistant energy subbands separated by $10.34 \mathrm{meV}$ within the $146 \mathrm{~nm}$ width PQW. The second design has 9 equidistant energy subbands separated by $28.95 \mathrm{meV}$ within the $52.2 \mathrm{~nm}$ width PQW. $\mathrm{THz}$ emission is realized through the intersubband carrier transitions successively from the upper down to the lowest subbands. Selection rules defined by the probability govern electron intersubband transitions and allowed transitions are between every 1st, 3rd, 5th, etc. neighbour subbands. However, the transitions between adjacent subbands have the greatest probability as compared to other ones. A relatively wide PQW if compared to rectangular QWs is in part responsible for greater stability over the applied external electric field and temperature.

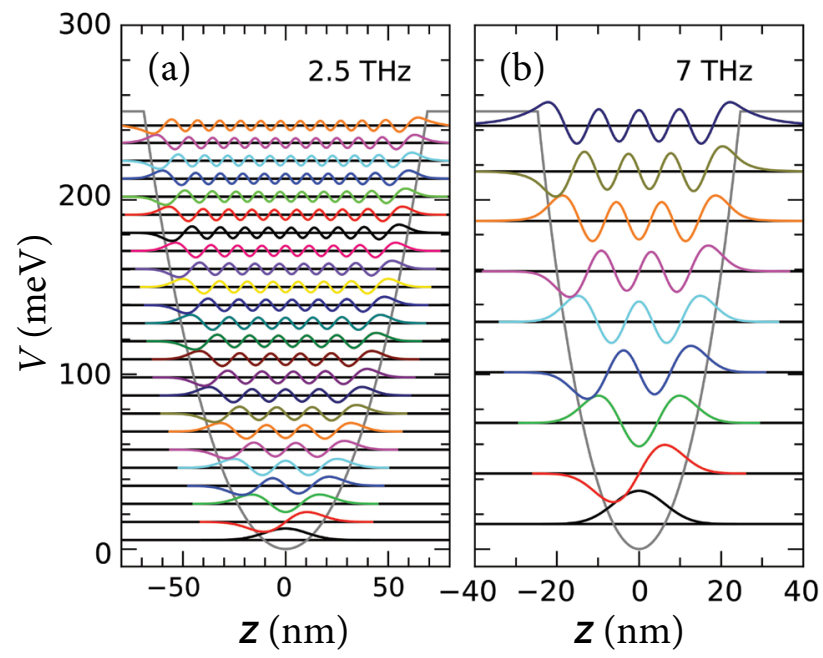

Fig. 1. PQW in the conduction band of GaAs/ $\mathrm{Al}_{0.3} \mathrm{Ga}_{0.7} \mathrm{As}$ structure for $2.5 \mathrm{THz}$ (a) and $7 \mathrm{THz}$ (b) emission. The width of PQW defines the energy separation between subbands. The $146 \mathrm{~nm}$ width PQW results in $10.34 \mathrm{meV}$ subband separation and 24 equidistant energy subbands in the well. The $52.2 \mathrm{~nm}$ width PQW results in $28.95 \mathrm{meV}$ subband separation and 9 equidistant energy subbands in the PQW.

In Fig. 2, the distance between subbands is depicted as a function of potential energy of the well. Better results were achieved with the quartic term added to the square one, as declared in Eq. (1). It effectively takes into account the influence of higher order electron effective mass change from GaAs to $\mathrm{Al}_{0.3} \mathrm{Ga}_{0.7}$ As. As a consequence, the modelled PQW width becomes narrower and it is 138.08 and $49.4 \mathrm{~nm}$ for 2.5 and $7 \mathrm{THz}$ designs, respectively. Even though the quartic term improved the arrangement of subbands in PQWs, the energy distance of the uppermost subbands decreases due to the finite barrier height, as seen in Fig. 2. This calculation result has a significant influence on the radiative power spectra that will be discussed latter.

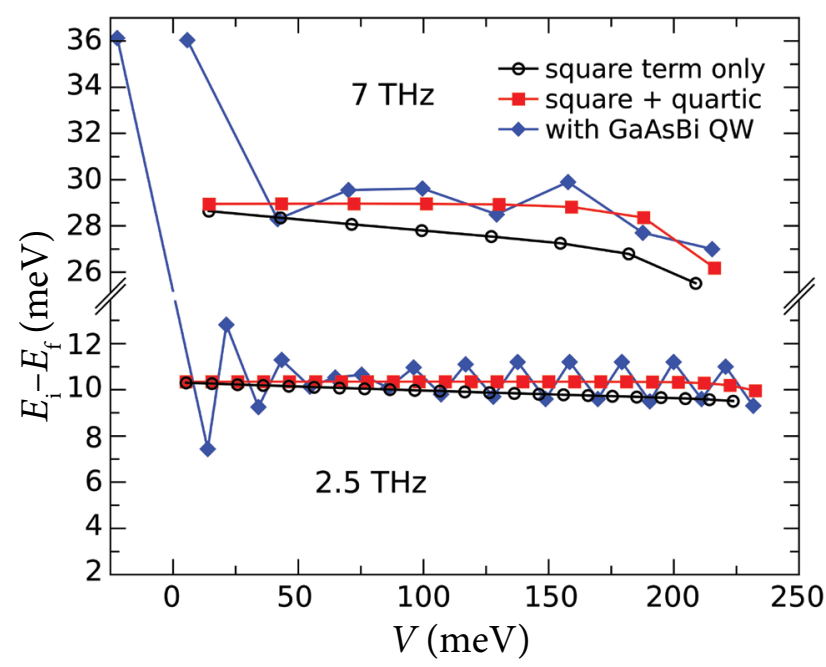

Fig. 2. Energy separation between the initial subband $E_{\mathrm{i}}$ and adjacent final subband $E_{\mathrm{f}}$ dependence on $E_{\mathrm{f}}$ in the PQW potential $V$ for 2.5 and $7 \mathrm{THz}$ design emitters. The open black dots show the energy separation calculated taking into account only the square term and solid red (online) squares show square and quartic terms in Eq. (1). The blue (online) diamonds show the energy separation for GaAs/AlGaAs PQW with $7 \mathrm{~nm} \mathrm{GaAsBi} / \mathrm{GaAs} \mathrm{QW}$ in the centre.

\subsection{Radiative lifetime}

One may expect that a greater number of subbands leads to higher power of radiation due to the overall number of electron transitions that contribute to the increase of single band emission. However, it is not true because radiative lifetime increases with a greater PQW width. It is the result of radiative lifetime being inversely proportional to the energy separation in the power of three and to the dipole matrix element in the power of two, as seen in Eqs. (4) and (5). It gives a non-trivial dependence of the radiative lifetime of intersubband transition on the frequency set by the design. 
To study this issue in more detail we modelled a number of PQWs with different well widths from $8.5 \mathrm{~nm}$ with only 2 subbands to $146 \mathrm{~nm}$ with 24 subbands in the well. The results are plotted in Fig. 3 , where the calculated radiative lifetime is depicted as a function of PQW width together with the subband separation energy and oscillator strength of the 2 lowermost subbands of PQWs. One can see that the relaxation time of radiative intersubband transition is increasing quadratically with a well width from $76 \mathrm{~ns}$ for the narrowest PQW up to $1.69 \mu$ s for $52.2 \mathrm{~nm}$ (7 THz design) PQW and $13.16 \mu$ s for $146 \mathrm{~nm}$ (2.5 THz design) PQW. The increase of lifetime is largely governed by the energy difference decrease. The oscillator strength also decreases with the increasing PQW width with the same dependence as the one for energy difference between the subbands versus PQW width. It means that intersubband transitions in the $\mathrm{THz}$ range are significantly weaker than in the infrared spectral range. Another interesting result (not shown here) is that the radiative lifetime is shorter for the transitions between upper subbands and extends for the transitions towards lower adjacent subbands.

\subsection{Depopulation and efficiency of spontaneous intersubband transition}

With the calculated lifetime one can roughly estimate the efficiency of $\mathrm{THz}$ emission with respect to other carrier scattering processes that take place in the quantum system. Various scattering processes have to be taken into account to evaluate the $\mathrm{THz}$ emission efficiency. In Fig. 4(a), a schematic representation of carrier excitation and relaxation processes is depicted. First of all, the carriers are (1) photoexcited with the laser radiation selectively from the uppermost valance to the uppermost conduction band PQW subbands. In the PQW with $h v_{\text {if }}<\hbar \omega_{\mathrm{LO}}$, where $\hbar \omega_{\mathrm{LO}}$ is LO phonon energy equal to $36 \mathrm{meV}$ for $\mathrm{GaAs}$, electrons can relax in one of the following scattering mechanisms: (2) spontaneous radiative intersubband transition to lower subbands of PQW emitting photons in the $\mathrm{THz}$ range, (3) non-radiative longitudinal acoustic (LA) phonon scattering, (4) electron scattering due to interface roughness, (5) non-radiative electron-electron scattering, and (6) spontaneous radiative interband transition.

The lifetime calculation with a simultaneous consideration of scattering processes is a quantum

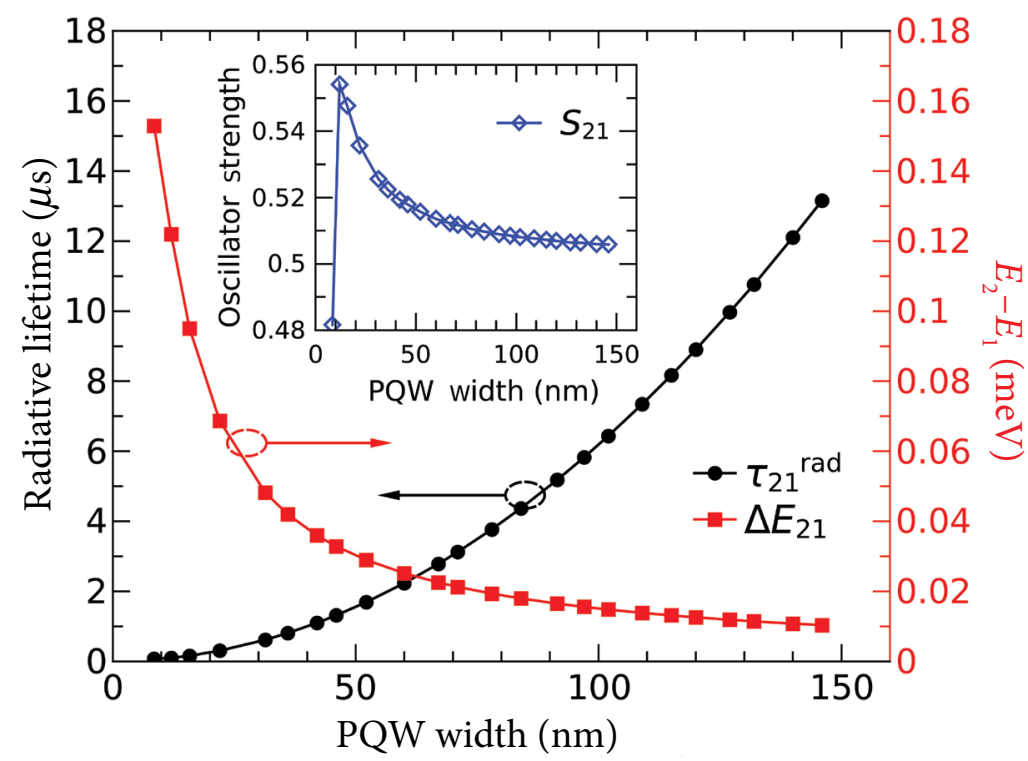

Fig. 3. Radiative lifetime $\tau_{21}^{\text {rad }}$ (black dots), equidistant energy difference between two lowermost subbands $\Delta E_{21}$ (red (online) squares) as a function of PQW width which defines the equidistant energy and emission frequency of $\mathrm{THz}$ emitter. The inset shows the oscillator strength $S_{21}$ (blue (online) diamonds) dependence on the PQW width. 
(a)

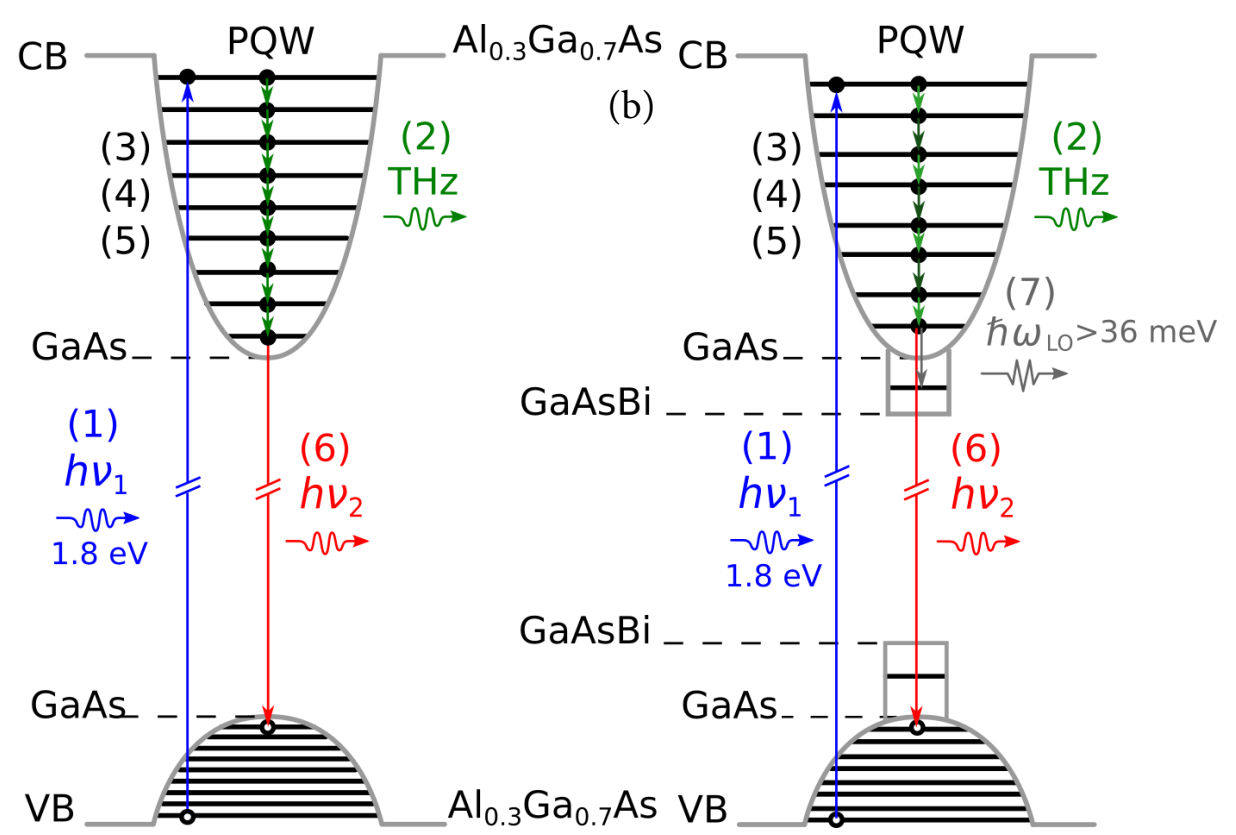

Fig. 4. Schematic diagram of the processes involved in carrier dynamics in the active area of PQW THz emitter without (a) and with (b) additional rectangular potential at the bottom of PQW: (1) absorption of excitation photon, (2) spontaneous radiative intersubband transition giving rise to $\mathrm{THz}$ radiation, (3) non-radiative acoustic phonon scattering, (4) electron scattering due to interface roughness, (5) non-radiative electron-electron scattering, (6) spontaneous radiative interband transition and (7) nonradiative optical phonon scattering.

mechanical problem which converges into solving the rate equations derived from the Fermi's golden rule for a particular quantum system. A number of theoretical studies addressing this problem have been carried out for GaAs/AlGaAs quantum structures owing to the fact that this material system is well-studied for practical applications, i.e. semiconductor lasers, QW infrared photodiodes, quantum cascade lasers, etc. In this work, for rough estimate we use the results available through the theoretical work by others $[42,43,35,44]$.

One can assume that there is enough excitation power density of laser radiation to reach the condition that the highest subbands of conduction band PQW be populated. Then five scattering processes that have the main contribution to carrier relaxation with characteristic lifetimes are taken into account. The relaxation time for LA phonon scattering is $250 \mathrm{ps}$ and electron scattering by interface roughness is $2 \mathrm{~ns}$ [43]. The non-radiative electron-electron scattering time constant is of 10 ps range [44]. For the radiative interband recombination the theoretical value of 20 ns may be used [42].
The quantum efficiency of the intersubband emission is given by the balance between the radiative and non-radiative relaxation processes and is calculated using

$$
\eta=\frac{R_{\mathrm{r}}}{R_{\mathrm{r}}+R_{\mathrm{nr}}}
$$

where $R_{\mathrm{r}}=1 / \tau_{\mathrm{if}}^{\text {rad }}$ is the intersubband transition rate for $\mathrm{THz}$ emission, and $R_{\mathrm{nr}}$ is the sum of all other processes that compete with the intersubband radiative one and reduce the efficiency of $\mathrm{THz}$ emission,

$$
R_{\mathrm{nr}}=\sum_{j}^{N} \frac{1}{\tau_{j}}
$$

where $N$ is the number of competing scattering processes with 4 abovementioned time constants. The efficiency of $\mathrm{THz}$ emission in the PQW drops down with the increase of $\tau_{\text {if }}^{\text {rad }}$ except for saturation to the limit of 1 at extremely fast transit times of less than 0.1 ps. Note that we have obtained the lowest time constant of 76 ns for the narrowest PQW of $8.5 \mathrm{~nm}$ in width yielding quantum efficiency $1.26 \times 10^{-4}$. In the case of designed PQWs 
for 7 and $2.5 \mathrm{THz}$ the efficiency is $5.66 \times 10^{-6}$ and $7.27 \times 10^{-7}$, respectively, with the above defined scattering times. The calculated efficiency value is two orders of magnitude greater than the reported experimental PQW device value $4.4 \times 10^{-8}$ [24].

Now, if we compare the scattering times, it becomes obvious that under the condition $h v_{\text {if }}<\hbar \omega_{\text {LO }}$ the fastest scattering process is the electron-electron interaction with a typical time constant of 10 ps range and the other ones remain much slower. However, to depopulate the lowest subbands of PQW to effectively remove the carriers, i.e. faster than from the upper subbands, one can introduce the LO scattering process with the typical time constant 0.2 ps [43]. Note that it is around 4 orders of magnitude shorter than that of the interface roughness scattering and 5 orders of magnitude shorter than the interband recombination. For comparison, the electron dephasing relaxation time in the subband is 0.14 ps [45]. With significantly shorter LO phonon scattering time the second subband of PQW is depopulated faster than the higher subbands. To widen the energy separation between the second and the first subbands, a rectangular $\mathrm{GaAsBi} / \mathrm{GaAs}$ QW may be formed in the centre of PQW, as shown in Fig. 4(b). In this new band arrangement the carriers from the upper subbands transit down to one adjacent subband with the highest probability and emit the $\mathrm{THz}$ photons. The electrons that reach the second subband are scattered with the LO phonons much faster than electrons from other subbands leaving the vacancy for other ones. It opens the possibility to depopulate the bottom of PQW and to overcome the carrier crowding effect which eventually stalls the $\mathrm{THz}$ generation due to the fact that $\tau_{\text {if }}^{\text {rad }}$ is greater for the transitions between lower subbands.

The subband arrangement changes with the rectangular potential added to the bottom of PQW. The simulations revealed that the optimal subband arrangement with the smallest deviation from the targeted subband separation (10.34 and $28.95 \mathrm{meV}$ ) is achieved with $7 \mathrm{~nm}$ well width and 1.7 and $0.45 \%$ Bi content in the GaAsBi/GaAs QW for 2.5 and $7 \mathrm{THz}$ designs, respectively. The energy separation between rearranged subbands is shown in Fig. 2. Now the energy separation between the first and the second subband is increased to $36 \mathrm{meV}$ and the energy separation between other subbands is deviated not more than the impact of quartic term to the parabolic dependence of potential energy on distance in Eq. (1). On the one hand, it can be tolerated for a broadband PQW based $\mathrm{THz}$ source. On the other hand, the subbands rearrangement has a significance to the dipole matrix element $d_{\mathrm{if}}$ the oscillator strength $S_{\text {if }}$ and the intersubband radiative lifetime $\tau_{\text {if }}^{\text {rad }}$.

The efficiency of the intersubband radiative process between the two lowermost subbands in PQW with the depopulation by LO phonon scattering is calculated using Eqs. (7) and (8). Now the number of competing scattering processes is 5 with the same time constants for each (see Fig. 4 and the attribution in the text). The LO phonon scattering reduces the efficiency by nearly 2 orders of magnitude and it is $1.16 \times 10^{-7}$ and $1.49 \times 10^{-8}$ for 7 and $2.5 \mathrm{THz}$ emitters, respectively. Therefore the carriers are effectively depopulated from the 2nd subband and these conditions may be favourable for electrons from higher PQW subbands to occupy the vacancies in lower energy states leading to enhancement in $\mathrm{THz}$ emission through the increase of intersubband radiative transition probability in the quantum system.

\subsection{Emission spectra}

Knowing the spontaneous radiative transition time $\tau_{\text {if }}^{\text {rad }}$ of every electron transition over all PQW subbands, one can calculate the emitted power spectrum of the given quantum system using Eq. (6). The radiative power spectra of PQWs are shown in Fig. 5. First, spectra for 2.5 and $7 \mathrm{THz}$ emission PQWs are calculated without an additional rectangular potential at the bottom of PQW. The emission spectrum of $2.5 \mathrm{THz}$ design shows the main spectral line at $2.48 \mathrm{THz}$ with two visible satellite lines at 7.5 and $12.5 \mathrm{THz}$ frequency, i.e. $5 \mathrm{THz}$ apart from each other. These are intersubband radiation maximums corresponding to the 3 rd and 5 th neighbour subbands with non-zero dipole matrix elements $d_{\mathrm{if}}$ The design for $7 \mathrm{THz}$ has the main emission line split with the maximum at $7 \mathrm{THz}$ and a weaker line at $6.36 \mathrm{THz}$ which is caused by transition between the uppermost subbands (see Figs. 1, 2). The satellite emission line due to electron transition to 
the 3rd neighbour subband is observed at 20.84 and $20.17 \mathrm{THz}$. Numerically significant non-zero $d_{\text {if }}$ elements for transitions to the 5th neighbour subbands in the case of $7 \mathrm{THz}$ design are situated already beyond the spectral range of interest at $35 \mathrm{THz}$ frequency and therefore that is not shown in Fig. 5 .

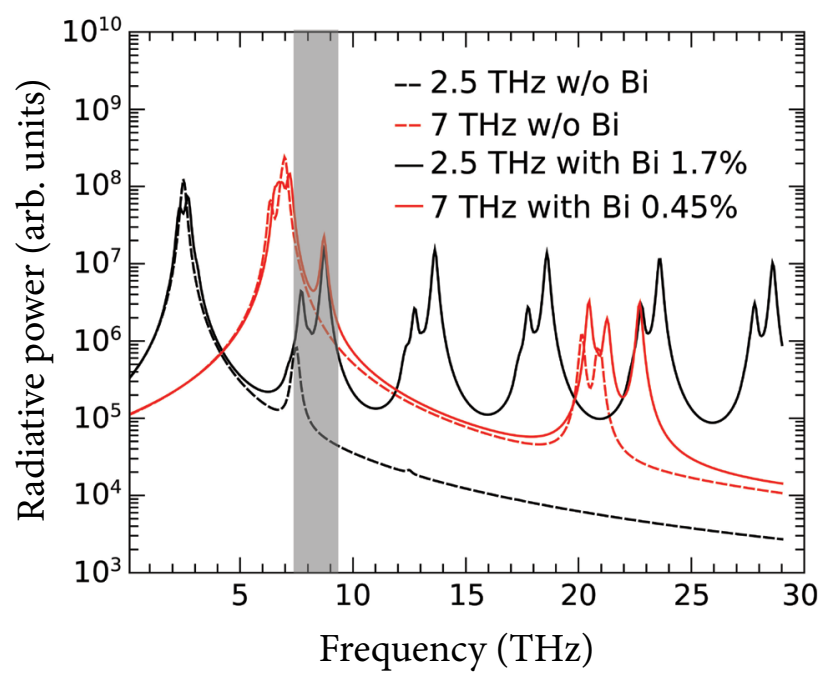

Fig. 5. Radiative power spectra of 2.5 and $7 \mathrm{THz}$ PQWs (dashed lines) and PQWs with GaAsBi/GaAs single QW at the centre (solid lines) for downshift of the first subband $36 \mathrm{meV}$ below the 2 nd subband to enable LO scattering of electrons. The gray area indicates the spectral interval for the reststrahlen region of GaAs.

The creation of additional potential with $\mathrm{GaAsBi} / \mathrm{GaAs} \mathrm{QW}$ in the centre of PQW changes the subbands energy arrangement and also the oscillator strength $S_{\text {if }}$ of intersubband transitions. As a result, the main radiative power spectra of PQWs are slightly wider due to the deviation from the equienergetic arrangement of subbands, but the intensity remains unchanged. Note that we have not taken into account the distribution of carriers over the subbands assuming it constant. It may change the intensity of spectral lines; however the intensity of satellite spectral lines changes dramatically due to a greater oscillation strength between the subbands because of the rearrangement. For the $2.5 \mathrm{THz}$ source design a significant increase is visible for electron transitions to every 3 rd, 5th, 7th and 9th neighbour subbands resulting in emission lines with peak intensity at 8.7, 13.6, 18.6, 23.6 and $28.5 \mathrm{THz}$, respectively. The same holds for the $7 \mathrm{THz}$ emitter. Note that the spectral lines that fall in the gray area are forbidden to travel in the structure due to the reststrahlen region of GaAs [32]. The intensity of satellite lines is also increased and a fine structure appears due to the deviation from the equidistant energy subbands arrangement. It can be beneficial for incoherent broad-band or multi-band $\mathrm{THz}$ emitters.

The modelled nanostructures of $\mathrm{GaAsBi} / \mathrm{GaAs}$ QW in GaAs/AlGaAs PQW can be realized using the molecular beam epitaxy technique for $\mathrm{THz}$ torch device fabrication. The $\mathrm{THz}$ torch device is proposed as an optically excited pin diode with the applied external electric field for carrier control in the PQW active region. The recent advance in the growth of GaAsBi epilayers and nanostructures [46, 47, 31] makes bismide an attractive option for $\mathrm{THz}$ emitters employing intersubband transitions instead of interband carrier recombination. The calculations show a significant influence of subband rearrangement to the radiation power spectra of $\mathrm{THz}$ torch due to the addition of rectangular $\mathrm{GaAsBi} / \mathrm{GaAs}$ potential to $\mathrm{AlGaAs} / \mathrm{GaAs}$ PQW for the carrier depopulation mechanism. More exact performance of the $\mathrm{THz}$ torch device can be modelled by solving the rate equations and calculating scattering time constants for the given quantum system as those are parameters sensitive to subband arrangement. The distribution of carriers over the PQW states also has a noticeable influence on emission spectra and efficiency. The builtin electric field needs to be taken into account in order to obtain a more complete description of the system performance. The working $\mathrm{THz}$ torch should be designed as a specific pin diode with reasonably doped layers for control of carrier density in the active area with quantum wells.

\section{Conclusions}

Incoherent $\mathrm{THz}$ emitting devices based on GaAs/ AlGaAs PQW with a central GaAsBi rectangular QW region are modelled for 2.5 and $7 \mathrm{THz}$ emission with a fast depopulation mechanism of the second to the first subband due to the carrier scattering with LO phonons. The energy separation between two lowermost subbands is widened by introducing an additional rectangular potential which is created by $\mathrm{GaAsBi} / \mathrm{GaAs} \mathrm{QW}$ at the centre of PQW. The introduced $7 \mathrm{~nm}$ wide GaAsBi QW 
with 1.7 and $0.45 \% \mathrm{Bi}$ content for 2.5 and $7 \mathrm{THz}$ emitters, respectively, increases the energy separation by more than $36 \mathrm{meV}$ to meet the LO phonon energy of GaAs maintaining at the same time the reasonably equidistant arrangement of upper subbands. The calculated radiative power spectra predict the broadening of spectral lines due to the rearrangement of subbands and the enhancement of satellite spectral lines as a result of the greater oscillation strength of transitions between rearranged subbands. Two designs are proposed for fabrication of a novel incoherent $\mathrm{THz}$ source, $\mathrm{THz}$ torch, with the introduced depopulation of carriers within PQW. It opens the possibility to enhance the $\mathrm{THz}$ emission through the increase of probability of intersubband radiative transitions in the proposed solid-state based quantum system.

\section{Acknowledgements}

This research has received funding from the European Social Fund (Project No. 09.3.3-LMTK-712-02-0172) under Grant Agreement with the Research Council of Lithuania (LMTLT).

\section{References}

[1] M. Karaliūnas, V. Jakštas, K.E. Nasser, R. Venckevičius, A. Urbanowicz, I. Kašalynas, and G. Valušis, Application of terahertz spectroscopy for characterization of biologically active organic molecules in natural environment, Proc. SPIE 9934, 99340P (2016).

[2] M. Karaliūnas, K.E. Nasser, A. Urbanowicz, I. Kašalynas, D. Bražinskienè, S. Asadauskas, and G. Valušis, Non-destructive inspection of food and technical oils by terahertz spectroscopy, Sci. Rep. 8, 18025 (2018).

[3] U. Puc, A. Abina, A. Jeglič, A. Zidanšek, I. Kašalynas, R. Venckevičius, and G. Valušis, Spectroscopic analysis of melatonin in the terahertz frequency range, Sensors 18(12), 4098 (2018).

[4] Q. Sun, Y. He, K. Liu, S. Fan, E.P.J. Parrott, and E. Pickwell-MacPherson, Recent advances in terahertz technology for biomedical applications, Quant. Imaging Med. Surg. 7(3), 345-355 (2017).
[5] J.-H. Son, S.J. Oh, and H. Cheon, Potential clinical applications of terahertz radiation, J. Appl. Phys. 125(19), 190901 (2019).

[6] I. Kašalynas, D. Seliuta, R. Simniškis, V. Tamošiūnas, K. Köhler, and G. Valušis, Terahertz imaging with bow-tie InGaAs-based diode with broken symmetry, Electron. Lett. 45, 833-835 (2009).

[7] I. Kasalynas, R. Venckevicius, and G. Valusis, Continuous wave spectroscopic terahertz imaging with InGaAs bow-tie diodes at room temperature, IEEE Sens. J. 13(1), 50-54 (2013).

[8] F. Wahaia, G. Valusis, L.M. Bernardo, A. Almeida, J.A. Moreira, P.C. Lopes, J. Macutkevic, I. Kasalynas, D. Seliuta, R. Adomavicius, R. Henrique, and $M$. Lopes, Detection of colon cancer by terahertz techniques, J. Mol. Struct. 1006(1-3), 77-82 (2011).

[9] I. Kašalynas, R. Venckevičius, L. Minkevičius, A. Sešek, F. Wahaia, V. Tamošiūnas, B. Voisiat, D. Seliuta, G. Valušis, A. Švigelj, and J. Trontelj, Spectroscopic terahertz imaging at room temperature employing microbolometer terahertz sensors and its application to the study of carcinoma tissues, Sensors 16(4), 432 (2016).

[10]O. Mitrofanov, I. Brener, T.S. Luk, and J.L. Reno, Photoconductive terahertz near-field detector with a hybrid nanoantenna array cavity, ACS Photonics 2(12), 1763-1768 (2015).

[11]T. Kiwa, T. Kamiya, T. Morimoto, K. Fujiwara, Y. Maeno, Y. Akiwa, M. Iida, T. Kuroda, K. Sakai, H. Nose, M. Kobayashi, and K. Tsukada, Imaging of chemical reactions using a terahertz chemical microscope, Photonics 6(1), 10 (2019).

[12]M. Tamošiūnaitè, V. Tamošiūnas, and G. Valušis, Wireless communications beyond 5G: Uncertainties of terahertz wave attenuation due to rain, Lith. J. Phys. 58(2), 149 (2018).

[13]I. Kašalynas, R. Venckevičius, D. Seliuta, I. Grigelionis, and G. Valušis, InGaAs-based bow-tie diode for spectroscopic terahertz imaging, J. Appl. Phys. 110(11), 114505 (2011).

[14]V. Jakštas, J. Jorudas, V. Janonis, L. Minkevičius, I. Kašalynas, P. Prystawko, and M. Leszczynski, Development of $\mathrm{AlGaN} / \mathrm{GaN} / \mathrm{SiC}$ high-electronmobility transistors for $\mathrm{THz}$ detection, Lith. J. Phys. 58(2), 188 (2018). 
[15]L. Minkevičius, V. Tamošiunas, K. Madeikis, B. Voisiat, I. Kašalynas, and G. Valušis, On-chip integration of laser-ablated zone plates for detection enhancement of InGaAs bow-tie terahertz detectors, Electron. Lett. 50(19), 1367 (2014).

[16]L. Minkevičius, S. Indrišiūnas, R. Šniaukas, B. Voisiat, V. Janonis, V. Tamošiūnas, I. Kašalynas, G. Račiukaitis, and G. Valušis, Terahertz multilevel phase Fresnel lenses fabricated by laser patterning of silicon, Opt. Lett. 42(10), 1875 (2017).

[17]D. Jokubauskis, L. Minkevičius, M. Karaliūnas, S. Indrišiūnas, I. Kašalynas, G. Račiukaitis, and G. Valušis, Fibonacci terahertz imaging by silicon diffractive optics, Opt. Lett. 43(12), 2795 (2018).

[18]D. Glaab, S. Boppel, A. Lisauskas, U. Pfeiffer, E. Öjefors, and H.G. Roskos, Terahertz heterodyne detection with silicon field-effect transistors, Appl. Phys. Lett. 96(4), 042106 (2010).

[19]L. Minkevičius, V. Tamošiūnas, I. Kašalynas, D. Seliuta, G. Valušis, A. Lisauskas, S. Boppel, H.G. Roskos, and K. Köhler, Terahertz heterodyne imaging with InGaAs-based bow-tie diodes, Appl. Phys. Lett. 99(13), 131101 (2011).

[20]D. Jokubauskis, L. Minkevičius, D. Seliuta, I. Kašalynas, and G. Valušis, Terahertz homodyne spectroscopic imaging of concealed low-absorbing objects, Opt. Eng. 58(2), 023104 (2019).

[21]W. Knap, S. Nadar, H. Videlier, S. BoubangaTombet, D. Coquillat, N. Dyakonova, F. Teppe, K. Karpierz, J. Łusakowski, M. Sakowicz, et al., Field effect transistors for terahertz detection and emission, J. Infrared Millim. Terahertz Waves 32(5), 618-628 (2011).

[22]V. Jakštas, I. Grigelionis, V. Janonis, G. Valušis, I. Kašalynas, G. Seniutinas, S. Juodkazis, P. Prystawko, and M. Leszczyński, Electrically driven terahertz radiation of 2DEG plasmons in AlGaN/ GaN structures at $110 \mathrm{~K}$ temperature, Appl. Phys. Lett. 110(20), 202101 (2017).

[23]R.C. Miller, A.C. Gossard, D.A. Kleinman, and O. Munteanu, Parabolic quantum wells with the GaAs-Al $\mathrm{Ga}_{1-x}$ As system, Phys. Rev. B 29, 3740 (1984).

[24]J. Ulrich, R. Zobl, K. Unterrainer, G. Strasser, E. Gornik, K.D. Maranowski, and A.C. Gossard, Temperature dependence of far-infrared electro- luminescence in parabolic quantum wells, Appl. Phys. Lett. 74(21), 3158 (1999).

[25]R. Bratschitsch, T. Müller, R. Kersting, G. Strasser, and $\mathrm{K}$. Unterrainer, Coherent terahertz emission from optically pumped intersubband plasmons in parabolic quantum wells, Appl. Phys. Lett. 76(24), 3501 (2000).

[26]H. Dakhlaoui, Tunability of the optical absorption and refractive index changes in step-like and parabolic quantum wells under external electric field, Optik 168, 416 (2018).

[27]M. Geiser, C. Walther, G. Scalari, M. Beck, M. Fischer, L. Nevou, and J. Faist, Strong lightmatter coupling at terahertz frequencies at room temperature in electronic LC resonators, Appl. Phys. Lett. 97(19), 191107 (2010).

[28]M. Geiser, F. Castellano, G. Scalari, M. Beck, L. Nevou, and J. Faist, Ultrastrong coupling regime and plasmon polaritons in parabolic semiconductor quantum wells, Phys. Rev. Lett. 108, 106402 (2012).

[29] A. Tzimis, A.V. Trifonov, G. Christmann, S.I. Tsintzos, Z. Hatzopoulos, I.V. Ignatiev, A.V. Kavokin, and P.G. Savvidis, Strong coupling and stimulated emission in single parabolic quantum well microcavity for terahertz cascade, Appl. Phys. Lett. 107(10), 101101 (2015).

[30]B. Paulillo, J.-M. Manceau, L.H. Li, A.G. Davies, E.H. Linfield, and R. Colombelli, Room temperature strong light-matter coupling in three dimensional terahertz meta-atoms, Appl. Phys. Lett. 108(10), 101101 (2016).

[31]S. Pūkienè, M. Karaliūnas, A. Jasinskas, E. Dudutienè, B. Čechavičius, J. Devenson, R. Butkutè, A. Udal, and G. Valušis, Enhancement of photoluminescence of GaAsBi quantum wells by parabolic design of AlGaAs barriers, Nanotechnology 30(45), 455001 (2019).

[32]M. Karaliunas, J. Pagalys, V. Jakštas, R. Norkus, A. Urbanowicz, J. Devenson, R. Butkute, A. Udal, and G. Valušis, Spectral properties of incoherent terahertz torch based on parabolic $\mathrm{Ga}(\mathrm{As}, \mathrm{Bi})$ / AlGaAs quantum wells, Proc. SPIE 11124, 1112409 (2019).

[33]P. Lautenschlager, M. Garriga, S. Logothetidis, and M. Cardona, Interband critical points of 
GaAs and their temperature dependence, Phys. Rev. B 35, 9174 (1987).

[34]I. Vurgaftman, J.R. Meyer, and L.R. Ram-Mohan, Band parameters for III-V compound semiconductors and their alloys, J. Appl. Phys. 89(11), 5815 (2001).

[35]T. Unuma, M. Yoshita, T. Noda, H. Sakaki, and H. Akiyama, Intersubband absorption linewidth in GaAs quantum wells due to scattering by interface roughness, phonons, alloy disorder, and impurities, J. Appl. Phys. 93(3), 1586 (2003).

[36]P. Harrison, Quantum Wells, Wires and Dots: Theoretical and Computational Physics of Semiconductor Nanostructures, 2nd ed. (John Wiley and Sons, Chichester, 2005) pp. 459.

[37]R. Reeder, Z. Ikonić, P. Harrison, A. Udal, and E. Velmre, Laterally pumped GaAs/AlGaAs quantum wells as sources of broadband terahertz radiation, Appl. Phys. Lett. 102(7), 073715 (2007).

[38]Q. Guo, C.K. Ong, H.C. Poon, and Y.P. Feng, Calculation of electron effective masses in AlAs, Phys. Status Solidi B 197(1), 111-117 (1996).

[39]V. Karpus, R. Norkus, R. Butkutè, S. Stanionyte, B. Čechavičius, and A. Krotkus, THz-excitation spectroscopy technique for band-offset determination, Opt. Express 26(26), 33807 (2018).

[40]I.P. Marko, S.R. Jin, K. Hild, Z. Batool, Z.L. Bushell, P. Ludewig, W. Stolz, K. Volz, R. Butkute, V. Pačebutas, A. Geizutis, A. Krotkus, and S.J. Sweeney, Properties of hybrid MOVPE/MBE grown $\mathrm{GaAsBi} / \mathrm{GaAs}$ based near-infrared emit- ting quantum well lasers, Semicond. Sci. Technol. 30(9), 094008 (2015).

[41]A. Udal, R. Reeder, E. Velmre, and P. Harrison, Comparison of methods for solving the Schrödinger equation for multiquantum well heterostructure applications, Proc. Estonian Acad. Sci. Eng. 12(2-3), 246 (2006).

[42]Y. Arakawa, H. Sakaki, M. Nishioka, J. Yoshino, and T. Kamiya, Recombination lifetime of carriers in GaAs-GaAlAs quantum wells near room temperature, Appl. Phys. Lett. 46(5), 519 (1985).

[43]R. Ferreira and G. Bastard, Evaluation of some scattering times for electrons in unbiased and biased single- and multiple-quantum-well structures, Phys. Rev. B 40, 1074 (1989).

[44]P. Harrison, Quantum Wells, Wires and Dots: Theoretical and Computational Physics of Semiconductor Nanostructures, 2nd ed. (John Wiley and Sons, Chichester, 2005) pp. 342.

[45]Y. Huang and C. Lien, Very large Stark shift in three-coupled-quantum wells and their application to tunable far-infrared photodetectors, J. Appl. Phys. 77(7), 3433 (1995).

[46]R. Butkute, V. Pačebutas, A. Krotkus, N. Knaub, and K. Volz, Migration-enhanced epitaxy of thin GaAsBi layers, Lith. J. Phys. 54(2), 125 (2014).

[47]R. Butkute, G. Niaura, E. Pozingyte, B. Čechavičius, A. Selskis, M. Skapas, V. Karpus, and A. Krotkus, Bismuth quantum dots in annealed GaAsBi/ AlAs quantum wells, Nanoscale Res. Lett. 12(1), 436 (2017). 


\title{
DEPOPULIACIJOS MECHANIZMAS NEKOHERENTINIAM TERAHERCŲ ŠALTINIUI - THz ŽIBINTUI, PAGRISTAM GaAsBi/GaAs KVANTINE DUOBE PARABOLINĖJE GaAs/AIGaAs KVANTINĖJE DUOBĖJE
}

\author{
M. Karaliūnas ${ }^{\text {a }}$ A. Udal ${ }^{\text {b }}$ G. Valušis ${ }^{\text {a }}$ \\ ${ }^{a}$ Fiziniu ir technologijos mokslu centras, Vilnius, Lietuva \\ ${ }^{\mathrm{b}}$ Talino technikos universitetas, Talinas, Estija
}

\section{Santrauka}

Parabolinès kvantinès duobès (PKD) yra žinomos kaip tinkama priemoné kompaktiškiems terahercų $(\mathrm{THz})$ šaltiniams. PKD turi vienodais energiniais tarpais pasiskirsčiusias pajuostes, kurios gali būti išdèstytos taip, kad būtų atskirtos kelių meV energiniu atstumu, - tai atitinka THz dažnių ruožą. THz spinduliuotès iš PKD našumui ir galiai padidinti siūlomas naujas būdas išnaudojant žemiausių PKD pajuosčių depopuliaciją. Darbe pateikiama nekoherentinio $\mathrm{THz}$ žibinto kaip prietaiso teorinè analizè. Rezultatai rodo, kad siauresnès draustinių energijų juostos GaAsBi / GaAs stačiakampès duobès ịterpimas ị GaAs / AlGaAs PKD gali pakeisti pajuosčių išsidèstymą taip, kad būtų ijungiamas greitesnis depopuliacijos mechanizmas, paremtas LO fononu sklaida. Suskaičiuoti spindulinès galios spektrai atskleidžia osciliatoriaus stiprio padidejimą tarp dèl pridèto GaAsBi stačiakampio potencialo persiskirsčiusių PKD pajuosčių. Išaugusi tarppajuostinio spindulinio šuolio tikimybe gali tapti našaus, kompaktiško, nekoherentinio THz šaltinio - THz žibinto - veikimo pagrindu. 